\title{
Low-Risk, Moderate-Risk, and Recreational Gambling Among Older Adults: Self-Complexity as a Buffer for Quality of Life
}

\author{
Margo Hilbrecht ${ }^{1,2}$ (D) Steven E. Mock $^{2}$
}

Received: 14 November 2017 / Accepted: 24 June 2018/Published online: 30 June 2018

(C) The Author(s) 2018

\begin{abstract}
Gambling is a popular activity among older adults that has potential for growth as the population ages. Benefits have been identified for recreational gamblers (those experiencing no gambling-related problems), but there are many social, financial, and health harms affecting quality of life related to gambling across the spectrum of risk levels. Because of their greater numbers, low and moderate risk (LMR) older adult gamblers are responsible for higher levels of population harm. Therefore, this study examines outcomes experienced by older adults who participate in gambling at recreational and LMR levels to better understand protective factors that contribute to quality of life. Guided by activity theory and a modified self-complexity model, we explore how leisure complexity and employment buffer the relationship between gambler type and factors associated with well-being, namely social support (both perceived and received) and stress. A sub-sample of 3232 adults, age 55 years and older, who gambled in the past year was drawn from the 2013-2014 Canadian Community Health Survey. Data were analyzed using linear regression with moderation, focusing on the interactions of gambling risk level with leisure complexity and employment. Recreational gamblers reported greater role complexity and more diverse leisure lifestyles, both of which were associated with greater social support and reduced stress. Life stress was higher among older adults who worked for pay. Even so, having a job appeared to temper stress levels among LMR gamblers, suggesting the
\end{abstract}

Margo Hilbrecht

margo@greo.ca

1 Gambling Research Exchange Ontario, 55 Wyndham St. N., Suite 214A, Guelph, ON N1H 7T8, Canada

2 Department of Recreation and Leisure Studies, University of Waterloo, 200 University Avenue West, Waterloo, ON N2L 3G1, Canada 
importance of maintaining a diversity of social roles and leisure activities, where possible, to enhance quality of life.

Keywords Olderadults·Low and moderateriskgambling - Quality oflife·Social support - Leisure complexity

Gambling research usually focuses on harmful activity, but most people who gamble do so recreationally and experience no related harms. For many older adults, recreational gambling is an entertaining social activity and, when undertaken responsibly, can enhance quality of life (van der Maas et al. 2016). Conversely, older adults who are problem gamblers experience diminished well-being in the form of poorer mental and physical health, compromised social functioning, and financial difficulties (Subramaniam et al. 2015). Between recreational and problem gamblers on the continuum of gambling behaviour are those with low and moderate risk levels (Ferris and Wynne 2001). These two mid-point groups compromise a relatively small percentage of the population, but because their numbers are greater than those identified as problem gamblers, they are responsible for greater amounts of harm at the population level than problem gamblers. (Browne et al. 2016). Although there is a growing literature addressing well-being outcomes for older adult problem gamblers, we know little about how low- and moderate-risk gambling may be linked to quality of life. This study explores the association of recreational and low- to-moderate risk levels of gambling with quality of life among adults age 55 and older. Further, if there are any harms associated with these levels of gambling, we examine potential buffers informed by a leisure and self-complexity lens.

\section{Background to the Study}

Gambling is a common leisure activity present throughout almost all cultures and time periods (McMillen 1996). In Canada, gambling was legalized federally in the early 1970 s, and amended in 1985 to give the provinces exclusive control over regulating gambling products such as slot machines, video lottery terminals, and lotteries (Korn 2000). As gambling has grown in popularity, stigma associated with illegal gambling and organized crime has diminished. In Canada, gambling participation rates for adults age 18 years and older range from a low of $66.6 \%$ in Quebec to a high of $86.6 \%$ in Saskatchewan (Canadian Partnership for Responsible Gambling 2015a). Clearly, gambling is a widely pursued leisure activity, but it has received limited attention from both leisure and quality of life researchers.

\section{Older Adult Gambling - Participation and Risk}

Gambling participation of older adults varies provincially, and the rate is generally lower than the overall adult population. In Ontario, for example, in 2011, 76.7\% of adults age 65 years and older reported gambling in the past year, compared to $82.9 \%$ of the overall population (Williams and Volberg 2013). In Quebec, 66.6\% of the adult 
population gambled in the past year, although participation among older adults varies by age with 55 to 64 year olds having the highest participation rate $(72.3 \%)$, adults age 65 to 74 years close to the average $(67.4 \%)$, and those aged 75 years or older, the lowest of all age groups (53.4\%) (Kairouz et al. 2014). This is consistent with other research findings that show participation rates are highest among the "young-old" and lower with older age groups (Vander Bilt et al. 2004; Zaranek and Chapleski 2005). Based on the volume of calls by older adults to problem gambling helplines, gambling may be increasing more quickly among older adults in North America than other age groups (McKay 2005). Gambling participation has the potential to increase further since older adults make up a growing percentage of the population. The greatest increase is projected to occur between 2013 and 2030, when those born during the Baby Boom generation reach 65 years and older (Bohnert et al. 2015).

Although many people gamble, problem gambling occurs in only a small percentage of the population (Canadian Partnership for Responsible Gambling 2015b). Gambling behaviour is typically classified along a continuum as non-problem, low-risk, moderate-risk, and problem gambling. Higher levels of psychological distress, greater financial expenditures, and lower levels of happiness typically occur at the upper end of the continuum (Currie et al. 2013; Farrell 2017; Shen et al. 2014). The most severe behaviour, gambling disorder, is currently the only behavioural addiction in the Diagnostic and Statistical Manual (DSM-5) of Mental Disorders (American Psychiatric Association 2013). In a systematic review of literature on the prevalence and determinants of problem gambling among older adults, the rate of gambling disorder ranged from $0.01 \%$ in Denmark to $10.6 \%$ in Connecticut, USA, with substantial variation due to different jurisdictions and age cut-offs for older adults, inconsistent measurement, and different sampling frames (Subramaniam et al. 2015). Non-problem and problem gamblers differ significantly across all dimensions, including playing patterns, mental health outcomes, and substance disorders, but there is some overlap between low and moderate risk groups on playing frequency and preferred game types, and for mental health and well-being (Currie et al. 2013). Low-risk gamblers experience very limited problems with few harmful consequences to themselves. For example, they may occasionally feel guilty about their gambling. Moderate risk gamblers have additional problems related to gambling and more often experience negative outcomes like relationship conflict, spending beyond their limit, and losing track of time (Browne et al. 2016).

\section{Benefits and Harms}

For most older adults, gambling is seen as fun activity, an enjoyable day out, and something they can participate in either on their own or as part of a group (Hope and Havir 2002). Non-problem gamblers generally view going to a casino as a safe and entertaining activity that includes opportunities to socialize, relieve boredom, experience excitement, and win money (van der Maas et al. 2017). The social aspect of gambling can be important for older adults. Gambling activities can lead to new social networks and provide an opportunity to reduce social isolation (Shaffer 2003). In a community-based, representative sample of older adults, going to the casino was seen, "as a community activity that brings people together" (Vander Bilt et al. 2004, p.388), especially for residents who were no longer employed. For older adults in community and assisted 
living centres, casino-related outings were identified as the most popular day trip, and bingo as the most popular on-location social activity (McNeilly and Burke 2001). When compared to older adults who do not gamble, recreational gamblers report better physical and mental health (Desai et al. 2004, 2007). The authors caution that the mechanism of this relationship is not well understood, and suggest that it may be related to more opportunities for social interaction. Vander Bilt et al. (2004) also found that gambling among older adults was linked to social support both at the present time and as anticipated in future. This suggests the overriding importance of social interaction and support, and that "in certain forms and contexts" (p. 387), gambling may be beneficial. Further, some types of gambling appear to help older adults with memory, concentration, math skills, and handeye coordination (Shaffer and Korn 2002).

Despite the positive contributions recreational gambling can make to quality of life, problem and pathological levels of gambling are associated with numerous harms. Harms can occur through direct effects (e.g., negative physiological arousal experienced while gambling) and indirect effects (e.g., longer-term negative consequences of financial loss and relationship damage) (Currie et al. 2009). Older adults may be especially vulnerable to problem gambling due to age-related stressors, such as feelings of isolation due to the death of a spouse and/or close friends, chronic health conditions that make it difficult to participate in other activities, boredom, and reliance on a fixed income (Ashe et al. 2008; Southwell et al. 2008). Older adult problem gamblers age 60 and over are more likely to experience social problems, physical health problems, and psychological difficulties than non-problem gamblers (Ariyabuddhiphongs 2012; Erickson et al. 2005; Pietrzak and Petry 2006; Tse et al. 2012). Others have noted that social isolation may make older adults vulnerable to higher levels of participation (Subramaniam et al. 2015; Tse et al. 2012). Older adults also report alcohol and substance dependencies more often (McCready et al. 2008). Longitudinal research documents the negative impact of problem gambling on social support, family functioning and relationship satisfaction (Cowlishaw et al. 2016). In addition to health and social harms linked to problem gambling, financial stress can be a critical harm associated with gambling for older adults (Ladd et al. 2003), since they may have few opportunities to recover lost resources (Southwell et al. 2008).

These harms are consistent with the taxonomy of harms outlined by Langham and her colleagues (2016). Drawing on diverse methodological approaches, dimensions of harm related directly or indirectly to problem gambling were identified as financial, relationship disruption, emotional, physical health, cultural, work performance, and criminal categories (Langham et al. 2016). These harms are not limited to problem gamblers, but also affect families, communities, and employers. By extending their focus to gamblers across the full range of gambling risk, the authors identified adults age 55 and older at low and moderate risk levels as responsible for the greatest amount of harm at the population level (Browne et al. 2016). Those in low and moderate risk categories can cause a greater amount of harm because there are simply more of them. Only a small minority remain in the at-risk category over a five-year period. Most transitioned to recreational gambling over time, although $14.7 \%$ ultimately became problem gamblers (Williams et al. 2015).

Until recently the dominant research focus has been on the relatively small percentage of problem gamblers (Hancock and Smith 2017), but the findings regarding low 
and moderate risk gamblers represent a general shift in research focus from prevalence to harm at the population level, and from individuals with severe gambling problems to those at any level of risk. Further, there has been much less research on non-problem, recreational gamblers despite calls for further investigation to better understand resiliency and protective factors that keep them from progressing toward higher risk levels (Abbott et al. 2015). We know little about this group, yet they are, by far, the overwhelming majority of older adults who gamble.

\section{Activity Theory, Self-Complexity, and Quality of Life}

Several theories have been advanced to explain leisure participation in later life. Activity theory proposes that by participating in activities, maintaining attitudes enjoyed during middle age, and finding substitutes for activities that can no longer be pursued, older adults will be able to maintain their quality of life. There is a positive link between activity and life satisfaction such that greater role loss is related to lower life satisfaction (Havighurst 1961). Being engaged in a number of activities is widely seen as important to aging successfully (Adams et al. 2010). Further, the social nature of activities is important to consider. Informal social interaction with family, neighbours, and friends, is seen to be especially important to quality of life, whereas formal interactions through groups and organizations, or solitary activities such as watching TV or reading may be less so (Lemon et al. 1972).

In a critical review of the aging and activity literature, Adams et al. (2010) found that social leisure and physical activities had the clearest association with well-being. Social activities were seen to provide social integration and support, while physical activities conferred numerous physical and mental health benefits. In particular, for older adults with loneliness, physically active leisure is linked to optimism, positive affect, and life satisfaction (Kim et al. 2017). Subramaniam et al. (2015) report that older adults may turn to gambling to deal with negative emotional states since they may have fewer opportunities for other exciting activities, previously enjoyed leisure activities may be limited or inaccessible, and gambling activities are seen to offer a substitute for social support.

Participation in a variety of activities may enhance quality of life because of the link to greater self-complexity. According to Linville's (1985) selfcomplexity model, the self consists of multiple, diverse aspects (e.g., partner, friend, employee, golfer, etc.). People vary both in the number and degree of independence or differentiation of these aspects, or roles, in their lives. Higher self-complexity is associated with more varied demands and experiences. When a stressful event occurs, it affects the self-aspect most relevant to the stressor. Greater self-complexity is seen to buffer stressful experiences. In other words, if things are not going well in one area, the overall repercussions are not as strong because there are other roles from which people with more differentiated selfcomplexity draw their sense of identity. Under stressful conditions, high selfcomplexity moderates the impact of stressful situations so that well-being declines less than would be expected for those with low self-complexity (Linville 1987).

Leisure activities can promote the development of self-complexity since leisure is a known source of identity formation and affirmation linked to self-concept and social 
interaction (Mannell and Manske 2010). The authors note that although there is an established literature on leisure as a stress coping mechanism (e.g., see Iwasaki 2003), complexity is more broadly associated with personal growth and psychological health. They also suggest that communities can play a role by providing opportunities for selfcomplexity development through meaningful leisure activities. Older adults can continue enjoying a diverse leisure repertoire providing they remain healthy and are not experiencing disability-related constraints (Stalker 2011). There is some evidence that leisure-generated complexity among older adults who gamble can enhance quality of life. Older adults with a wide range of leisure activities and who had ranked gambling as relatively less important were four times less likely to be at risk of problem gambling compared to those who viewed gambling as a central part of their leisure lifestyle (Pietrzak et al. 2007). For older adults who pursue multiple leisure activities, gambling is among the least favourite (Zaranek and Chapleski 2005), whereas for older adults with limited leisure opportunities, gambling ranks among the highest (McNeilly and Burke 2001).

To summarize, gambling is a common activity among older adults. Although participation rates are lower than for the overall adult population, greater numbers of older adults are gambling due to population aging. Motivations include factors such as entertainment, socializing, and a pleasant outing, but there are sometimes complex underlying issues such as boredom, isolation, and coping with age-related transitions such as retirement, the death of a spouse, and physical health conditions that limit participation in other activities. Most older adults who gamble experience no related harms and even some benefits. A small percentage, however, is classified as low risk, moderate risk, or problem gamblers. Using validated psychological measures, most research to date has focused on problem gamblers who experience the highest amounts of personal, relationship, and financial stress. Recent research indicates that older adult gamblers at low and moderate risk levels are responsible for the greatest amounts of harm since there are simply more people belonging to these risk categories. Even so, attention to these groups has been limited. Activity theory suggests that for successful aging, older adults need to continue with activities or find substitutes for those pursued when younger. Gambling may become a substitute for other leisure or work roles as adults become older. The self-complexity model proposes that people who have a greater number of differentiated roles or self-aspects are better able to cope with stressors since their self-identity extends to multiple activities. For those who gamble, greater self-complexity related to different roles and leisure activities could buffer stressful situations related to low or moderate risk levels and contribute to quality of life.

To date, little research has focused on recreational gamblers to better understand meaningful protective factors linked to well-being and productive aging (Tse et al. 2012). Since broader harms associated with older adult gamblers are concentrated among the low and moderate risk groups, we view this group as worthy of greater attention. This study seeks to address this gap by comparing quality of life among recreational gamblers to those identified as low and moderate risk gamblers. To do so, we adopt an activity and self-complexity lens to explore what factors buffer the relationship between type of gambler and well-being. We focus on leisure and selfcomplexity since they have been identified as contributors to social support and lower stress levels. 


\section{Method}

The data source for this study was the annual component of Statistics Canada's 20132014 Canadian Community Health Survey (CCHS), Public Use Microdata Files. The survey is conducted every 2 years and collects information on Canadians' health status, determinants of health, and use of heath care services. By providing timely information, the goal is to help capture emerging issues related to Canadians' health. Data were collected throughout 2013 and 2014 from one member, age 12 and older, of each randomly selected household (Statistics Canada 2015). All provinces and territories were included in the survey.

\section{Participants}

Although 128,310 people participated in the CCHS, the Problem Gambling module was optional and only four provinces elected to take part: Quebec, Manitoba, Saskatchewan, and British Columbia. Similarly, questions assessing social support were part of an optional Social Provisions module in which only Quebec and Nova Scotia participated (Statistics Canada 2015). Given the contribution of variables from both modules to addressing the research questions, only residents of Quebec could be included in the study. Within this geographic parameter, a subsample was drawn of adults age 55 years or older who had gambled in the past 12 months and who provided a response when asked whether they had worked at a job or business during the past week. We excluded problem gamblers from the analyses for two reasons: (1) only $0.8 \%$ of the subsample was identified as a problem gambler $(n=25)$, thereby limiting the statistical power; and, (2) people in the PG group may share similar individual and social factors that make them particularly vulnerable (Abbott et al. 2015). Since much is already known about detrimental effects on quality of life experienced by problem gamblers, we have chosen to focus on older adults in the recreational and low to moderate risk groups to add to the understanding of these groups. The final subsample size was $n=3232$.

\section{Measures}

\section{Socio-Demographic Characteristics}

Socio-demographic factors used in the analysis included age, gender, education, household income, and marital status. Age is grouped into 5-year increments in the CCHS. Of the 16 age groups, only categories for participants age 55 years and older were selected. Categories were then converted to years by using the mid-point of the age group (e.g., $57=$ ' 55 to 59 ', $62=$ ' 60 to 64 ', etc.). Gender is indicated as female $=0$ or male $=1$. Level of education is assessed using four categories: 'less than secondary school' $=1$, 'secondary school graduate' $=2$, 'some post-secondary education' $=3$, and 'post-secondary certificate' $=4$. Household income represents total annual income from all sources. It is grouped into five categories ranging from 'less than $\$ 20,000$ ' $=1$ to ' $\$ 80,000$ or more' $=5$. Marital status is categorized as married, common-law, widowed/ separated/divorced, and single/never married. For the analyses, marital status is recoded as 'partnered' $=1$ for those who were married or cohabiting, and 'not partnered' $=0$ for people who selected another marital status category. 


\section{Activity Factors}

There is a limited number of leisure and main activities in the CCHS that could contribute to aspects of self-identity. Two other factors in addition to gambling that were considered: total leisure participation or, leisure complexity, and employment.

Gambler type Participants completed the Problem Gambling Severity Index (PGSI). The PGSI is a 9-item index that measures gambling behaviour and its consequences. It is a shortened version of the 31-item Canadian Problem Gambling Index (Ferris and Wynne 2001). The PGSI shows strong reliability and internal validity (Currie et al. 2013), and is a commonly used measure of gambling severity. Examples of questions included in the index are "When you gambled, did you go back another day to try to win back the money you lost?", "Has your gambling caused any financial problems for you or your household?", and "How often have you bet more than you could really afford to lose?". Responses were reported along a 4-point scale where 'never' $=0$, 'sometimes' = 1, 'most of the time' $=2$, and 'almost always' $=3$, and then summed for an overall score ranging from 0 to 27 . Along this continuum, a person with a score of zero is deemed a non-problem gambler while someone with a score of 8 or above is classified as a problem-gambler. For this study, the term non-problem gambler is used interchangeably with recreational gambler.

There has been some debate about the validity of PGSI cut-off levels for low-risk and moderate-risk gamblers. Extensive testing has revealed that both groups are significantly different from non-problem and problem gamblers, but there were few meaningful differences between the low- and moderate-risk groups using the original cut-off values. Rescoring was proposed to ensure that each category was distinct, so that low-risk gamblers score between 1 to 4 on the PGSI and moderate-risk gamblers score between 5 to 7 (Currie et al. 2013). Based on these recommendations and with the ongoing debate about cut-off scores in mind, we grouped low- and moderate-risk gamblers into one category (PGSI score of 1 through 7). Using this cut-off, gambling type is either recreational $=0$ or low- or moderate-risk gambler $(L M R)=1$. We note that concerns have also been expressed about using the PGSI in relation to harm since not all items on the 9-item scale address harm directly and there is a tendency to conflate behaviour and harm (Delfabbro and King 2017). However, Browne et al. (2016) conducted cross-tabulations of seven harm categories (using a 73-item harms scale capturing harm across seven main dimensions) with PGSI level and results clearly indicated that higher levels of harm were present as gambling risk level increased.

Leisure complexity Leisure complexity indicates the number of different physically active leisure pursuits in which participants engaged during the previous 3 months. The 22 possible options in the CCHS included activities such as walking, gardening, swimming, home exercise, playing tennis, golfing, and fishing, with an additional category for "other activity". For each activity a score of one was assigned if the respondent had participated at least once in the past 3 months, and zero was assigned if he or she had not participated. The score for all activities was summed for an overall leisure complexity measure, which ranged from 0 to 22 . Although it would be preferable to include a wider variety of leisure activities like reading or watching TV, these were not included in the complexity measure since they were part of an optional 
Sedentary Activity module not administered in Quebec. Other activities, such as informal socializing, pursuing hobbies, or attending a movie, cultural, or sport event were not included in the survey.

Employment Participants were asked whether they had worked at a job or business at any time in the past 12 months ("No" $=0$ or "Yes" =1). No further information was available about job quality, employment sector, number of hours, work schedule, or occupational class.

\section{Quality of Life Factors}

We use quality of life and well-being interchangeably, understanding that there is debate over differences in regard to subjective and objective evaluation as well as single item and multi-dimensional measures (e.g., see Cummins 2000; Krueger and Schkade 2008). Well-being is operationalized in various ways, but there is no consistent use or overall agreement on the meaning or measurement (Kekäläinen et al. 2017). For this study, we include psychological, social and physical measures related to wellbeing. We focus on two subjectively evaluated factors related to quality of life, one social and the other psychological: social support and life stress as dependent variables. We include self-assessed health as a control variable to represent physical health.

Social support The Social Provisions Scale is a multidimensional assessment of social support that is divided into two main categories of assistance-related and non-assistance related provisions (Cutrona and Russell 1987). Both types of support are conceptually different, and the importance of each can vary according to life cycle stage and specific life events. Together, they contribute to life satisfaction and are deemed necessary for feelings of adequate social support. The CCHS uses an abbreviated version of the scale developed by Caron (1996). Each subscale consists of two items that are able to maintain the psychometric properties of the original scale.

The CCHS includes five subscales in the Social Provisions module. Of these, two were selected that represent each of the main social support categories. The subscales, each consisting of two items, were considered the most salient for older adults who may be undergoing major life transitions such as retirement, experiencing age-related health decline, or dealing with the death of a loved one. In such situations, both types of support would be helpful in reducing stress and contributing to quality of life. The first subscale, Guidance, is an assistance-related social provision in the form of advice or informational support (e.g., "There is someone I could talk to about important decisions in my life", and "There is a trustworthy person I could turn to for advice if I were having problems"; $r=.72$ ). It is a received form of support, that is, enacted or actual assistance which is especially relevant to problem-solving in the face of stress (Barrera 1986). The other subscale, attachment, represents emotional closeness and is related to feelings of security (e.g., "I feel a strong bond with at least one other person", and "I have close relationships that provide me with a sense of emotional security and well-being"; $r=.65$ ). This represents perceived support, that is, feelings that someone would be there for you when in need (Barrera 1986). For each subscale item, participants rated the extent to which they agreed with each statement, ranging from "strongly disagree" $=1$ to "strongly agree" = 
4. A sum of the items was calculated to generate a measure of each type of social provision.

Life Stress Life stress was a single-item measure. Participants were asked, "Thinking about the amount of stress in your life, would you say that most days are...". They responded along a 5-point scale where $1=$ "Not at all stressful" and $5=$ "Extremely stressful".

Self-assessed health People described their overall health along a 5-point scale where "Excellent" = 1 and "Poor" = 5. This factor was reverse coded so that higher numbers indicated feelings of better health. Single-item measures of psychological and physical health have shown good validity and reliability (DeSalvo et al. 2006; Robins et al. 2001), as well as substantial predictive ability (Kaplan and Camacho 1983).

\section{Plan of Analysis}

Descriptive statistics were assessed, then recreational and LMR gamblers were compared on all factors selected for inclusion using Chi-square tests or independent samples t-tests with survey weights adjusted for the subsample. Three linear regression models examined how self-complexity contributed to the relationship between gambler status and quality of life. The first two models tested the effect of activity factors, including gambler type, leisure complexity, and employment on social support, using separate models for guidance and attachment. The third model tested the effect of these activity factors on life stress. The first model of the regression analysis controlled for confounding factors including age, gender, education, household income, marital status, and self-assessed health. The second model added the activity-related variables. Interactions were tested between gambler type and employment, and gambler type and leisure complexity. Where interactions were significant, they were probed further using Hayes' PROCESS macro (Hayes 2013). This allowed us to explore the simple slopes for the relationship of the focal variable (gambler type) with the criterion variable (i.e., quality of life factor) at low and high levels of the moderator variables (leisure complexity, employment).

\section{Results}

\section{Sample Characteristics}

Of the 3232 older adults who had gambled in the past year (excluding problem gamblers), $4.2 \%(n=135)$ were classified by their PGSI score as low or moderate risk (LMR) gamblers, and the remaining 95.8\% $(n=3097)$ as non-problem, or recreational gamblers. The average age was 63.7 years $(S D=5.34), 48.4 \%$ were men, and $68.2 \%$ were either married or cohabiting. The mean household income was $3.61(S D=1.34)$ which is roughly equivalent to $\$ 63,000 \mathrm{CAD} ; 61.3 \%$ were educated beyond the high school level; and, $50.8 \%$ were employed. See Table 1 for a complete list of descriptive statistics of all variables included in the models. 
Table 1 Sample characteristics $(n=3232)$

\begin{tabular}{|c|c|c|}
\hline Variables & $M /$ Pct. & $S D$ \\
\hline \multicolumn{3}{|l|}{ Demographics } \\
\hline Age (55-74 years) & 63.7 & 5.34 \\
\hline Male & 48.2 & - \\
\hline Partnered & 68.2 & - \\
\hline \multicolumn{3}{|l|}{ Education } \\
\hline Less than secondary school graduate & 19.0 & - \\
\hline Secondary school graduate & 19.7 & - \\
\hline Some post-secondary education & 4.7 & - \\
\hline Post-secondary certification & 56.6 & - \\
\hline Household income & 3.26 & 1.34 \\
\hline$\$ 0$ to $<\$ 20,000$ & 9.6 & - \\
\hline$\$ 20,000$ to $\$ 39,999$ & 24.9 & - \\
\hline$\$ 40,000$ to $\$ 59,999$ & 22.6 & - \\
\hline$\$ 60,000$ to $\$ 79,999$ & 15.9 & - \\
\hline$\$ 80,000$ or more & 27.0 & - \\
\hline \multicolumn{3}{|l|}{ Activity factors } \\
\hline Low or moderate risk gambler & 4.2 & - \\
\hline Level of leisure complexity (0-22) & 2.66 & 1.09 \\
\hline Employed & 50.8 & - \\
\hline \multicolumn{3}{|l|}{ Quality of life } \\
\hline Self-assessed health (1-5) & 3.56 & .98 \\
\hline Social support - Attachment (1-10) & 7.04 & 1.09 \\
\hline Social support - Guidance (1-10) & 7.03 & 1.10 \\
\hline Life stress $(1-5)$ & 2.50 & 1.06 \\
\hline
\end{tabular}

Factors associated with being an LMR gambler were compared to recreational gamblers. More men than women were LMR gamblers $\left(X^{2}=7.39, p=.008\right)$, and more recreational gamblers were partnered when compared to LMR gamblers $\left(X^{2}=\right.$ $79.25, p=.003)$. There were no differences by gambler type in terms of age, level of education, household income, employment status, or self-assessed health. Significant differences were identified for level of leisure complexity $(t=2.68, p=.013)$, with recreational gamblers reporting participation in a broader range of leisure activities than LMR gamblers. Recreational gamblers also had stronger social support in relation to both guidance $(t=3.73, p<.001)$ and feelings of attachment $(t=6.27, p<.001)$. The groups reported similar levels of life stress.

\section{Regression Models}

\section{Social Support - Guidance}

In Model 1, all socio-demographic variables were significant with the exception of marital status. Older age groups and men indicated less received support in 
the form of guidance, while being partnered, more highly educated, having a higher household income, and feeling healthier were all positively associated with access to supportive guidance (see Table 2). In Model 2, the same sociodemographic variables remained significant. Of the activity variables, being an LMR gambler was negatively related to guidance. In Model 3, all previous significant relationships remained, and both interactions were significant (see Table 2).

Probing of the interactions showed that for those who were employed, the association of LMR gambling status (versus recreational gambling) was weaker than LMR gambling status (versus recreational gambling) for those who were not employed $(b=$ $-.44, S E=.18, p=.016$ versus $b=-.78, S E=.17, p<.001$, respectively: see Fig. 1). This highlights the contribution of employment in terms of increased access to supportive guidance among LMR gamblers.

Similarly, higher levels of leisure complexity appear to buffer LMR gamblers from any reduction in supportive guidance $b=-.15, S E=.19, p=.432$; see Fig. 2) compared to those with lover levels of leisure complexity ( $b=-.66$, $S E=.14, p<.001$; see Fig. 2). This suggests that participating in a greater variety of leisure activities buffers the association that would normally be found between LMR gamblers (versus recreational gamblers) and lower levels of social support.

Table 2 Unstandardized coefficients for regression models showing the association of selected demographics, activities, and interaction terms with supportive guidance

\begin{tabular}{|c|c|c|c|c|c|c|}
\hline \multirow[t]{2}{*}{ Independent variables } & \multicolumn{2}{|l|}{ Model 1} & \multicolumn{2}{|l|}{ Model 2} & \multicolumn{2}{|l|}{ Model 3} \\
\hline & $\mathrm{B}$ & SE & $\mathrm{B}$ & SE & $\mathrm{B}$ & SE \\
\hline Constant & $6.98^{* * * *}$ & .26 & $6.93^{* * * *}$ & .28 & $6.98^{* * * *}$ & .28 \\
\hline \multicolumn{7}{|l|}{ Demographics and health } \\
\hline Age & $-.01^{* *}$ & .00 & $-.01^{*}$ & .00 & $-.01^{* *}$ & .00 \\
\hline Gender $($ Male $=1)$ & $-.39^{* * * *}$ & .04 & $-.40^{* * * *}$ & .04 & $-.40^{* * * *}$ & .04 \\
\hline Partnered & .07 & .04 & .07 & .04 & .07 & .04 \\
\hline Education & $.19^{* * * *}$ & .04 & $.18^{* * * *}$ & .04 & $.18^{* * * *}$ & .04 \\
\hline Household income & $.10^{* * * *}$ & .02 & $.09^{* * * *}$ & .02 & $.09^{* * * *}$ & .02 \\
\hline Self-assessed health & $.12^{* * * *}$ & .02 & $.11^{* * * *}$ & .02 & $.12^{* * * *}$ & .02 \\
\hline \multicolumn{7}{|l|}{ Activities } \\
\hline Low or mod. risk gambler & & & $-.33^{* * *}$ & .09 & $-.79^{* * * *}$ & .17 \\
\hline Leisure complexity & & & .20 & .01 & .01 & .01 \\
\hline Employed & & & .02 & .05 & .01 & .05 \\
\hline \multicolumn{7}{|l|}{ Interactions } \\
\hline Gambler $\mathrm{x}$ employed & & & & & $.35^{*}$ & .05 \\
\hline Gambler x leis. Complexity & & & & & $.13^{*}$ & .05 \\
\hline Adj. $R^{2}$ & .082 & & .086 & & .089 & \\
\hline
\end{tabular}

$n=3129 ; * p<.05, * * p<.01, * * * p<.001$ 


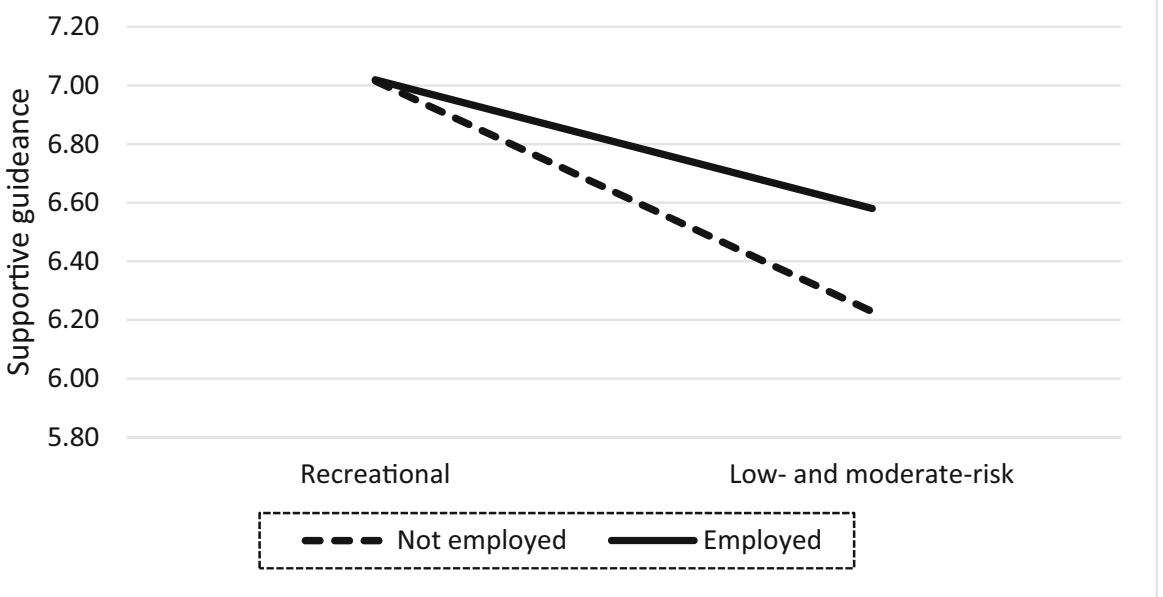

Fig. 1 Supportive guidance by type of gambler and employment status (adults 55 years and older)

\section{Social Support - Attachment}

In Models 1 and 2, all socio-demographic factors were significantly associated with feelings of attachment. Older age groups and men had lower levels of social attachment than other participants, while having a partner, more education, a higher income level, and better self-assessed health were positively related to attachment (see Table 3). With the introduction of activity factors in Model 2, the socio-demographic factors were still significant, but of the activity factors only leisure complexity was significantly, positively associated with feelings of attachment. When the interactions were introduced in Model 3, the socio-demographic factors remained significant, although self-assessed health was no longer-significant. There was a strong, negative relationship for gambler type, with LMR gamblers reporting lower levels of attachment. Significant effects were found for both interactions (see Table 3).

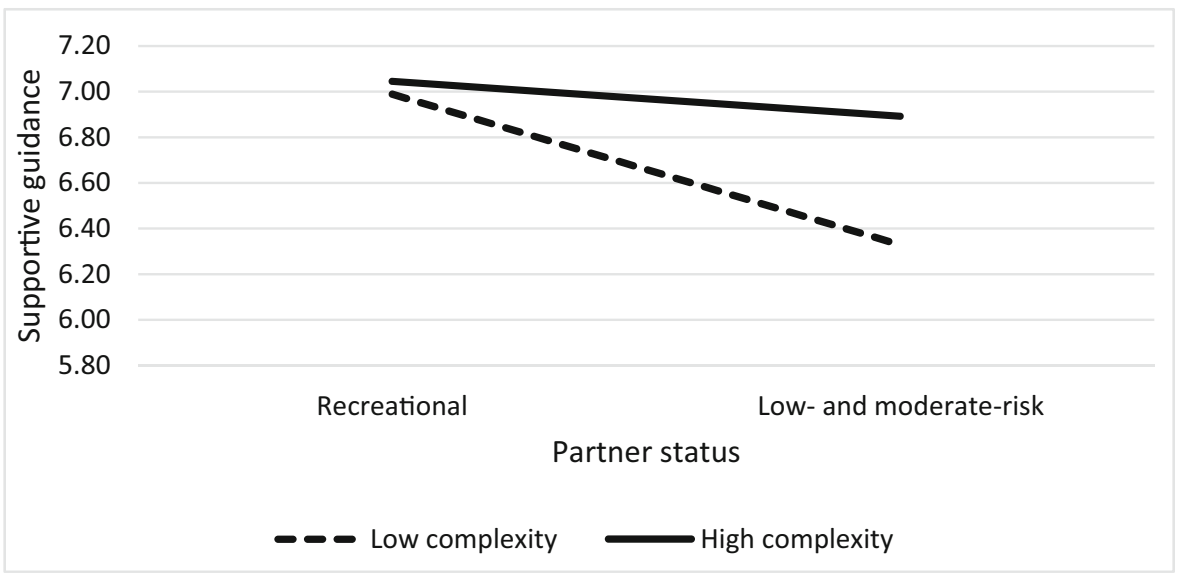

Fig. 2 Supportive guidance by type of gambler and level of leisure complexity (adults 55 years and older) 
Table 3 Unstandardized coefficients for regression models showing the association of selected demographics, activities, and interaction terms with social attachment

\begin{tabular}{|c|c|c|c|c|c|c|}
\hline \multirow{2}{*}{ Independent variables } & \multicolumn{2}{|l|}{ Model 1} & \multicolumn{2}{|l|}{ Model 2} & \multicolumn{2}{|l|}{ Model 3} \\
\hline & B & SE & $\mathrm{B}$ & SE & $\mathrm{B}$ & SE \\
\hline Constant & $7.00^{* * * *}$ & .26 & $7.12^{* * * *}$ & .28 & $7.18^{* * * *}$ & .28 \\
\hline \multicolumn{7}{|l|}{ Demographics and health } \\
\hline Age & $-.01^{* * * *}$ & .00 & $-.01^{* * * *}$ & .00 & $-.02^{* * * *}$ & .00 \\
\hline Gender $($ Male $=1)$ & $-.38^{* * * *}$ & .04 & $-.38^{* * * *}$ & .04 & $-.38^{* * * *}$ & .04 \\
\hline Partnered & $.18^{* * * *}$ & .04 & $.17^{* * * *}$ & .04 & $.17^{* * * *}$ & .04 \\
\hline Education & $.18^{* * * *}$ & .04 & $.17^{* * * *}$ & .04 & $.17^{*}$ & .04 \\
\hline Household income & $.09^{* * * *}$ & .02 & $.09^{* * * *}$ & .02 & $.08^{* * * *}$ & .02 \\
\hline Self-assessed health & $.13^{* * * *}$ & .02 & $.12^{* * * *}$ & .02 & .13 & .02 \\
\hline \multicolumn{7}{|l|}{ Activities } \\
\hline Low or mod. risk gambler & & & -.15 & .09 & $-.76^{* * * *}$ & .17 \\
\hline Leisure complexity & & & $.03^{* *}$ & .01 & .02 & .01 \\
\hline Employed & & & -.05 & .05 & -.07 & .05 \\
\hline \multicolumn{7}{|l|}{ Interactions } \\
\hline Gambler $\mathrm{x}$ employed & & & & & $.36^{*}$ & .18 \\
\hline Gambler $x$ leis. Complexity & & & & & $.19^{* * * *}$ & .05 \\
\hline Adj. $R^{2}$ & .087 & & .090 & & .094 & \\
\hline
\end{tabular}

$n=3167 ; * p<.05, * * p<.01, * * * p<.001$

For the interaction between gambler type and employment status, for those who were employed, social attachment was somewhat lower for LMR compared to recreational gamblers $(b=-.42, S E=.18, p=.028$; see Fig. 3$)$, but the relationship was weaker than for those who were not employed $(b=-.76, S E=.17, p<.001$; see Fig. 3 ). This suggests that employment could allow people to develop and sustain feelings of emotional closeness that positively effect quality of life, especially for LMR gamblers.

The interaction between gambler type and leisure complexity was also significant. For older adults with higher levels of leisure complexity there is no difference in social attachment between recreational and LMR gamblers $(b=.19, S E=.20, p=.323$; see Fig. 4). Among older adults who reported less leisure complexity, LMR gamblers had lower levels of attachment than recreational gamblers $(b=-.57, S E=.14, p<.001$; see Fig. 4). This indicates that a diverse leisure lifestyle buffers the association between LMR gambling and feelings of attachment so that they continue to perceive stronger social support than LMR gamblers who have less diversity in their leisure pursuits.

\section{Life Stress}

In Model 1, belonging to an older age group, being male, and having better self-assessed health was negatively associated with feelings of stress, while a higher income level was positively related to life stress (see Table 4). With the addition of activity variables in Model 2, the same factors remained significant. In addition, being an LMR gambler was positively 


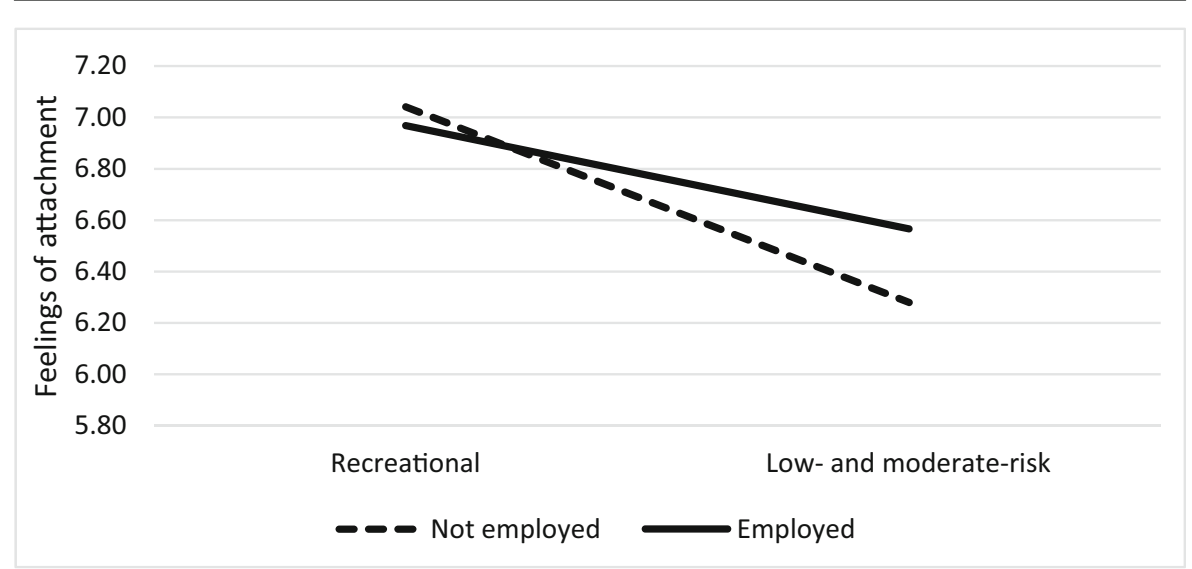

Fig. 3 Social attachment by type of gambler and employment status (adults 55 years and older)

associated with life stress, as was having a job (see Table 4). This pattern continued in Model 3 , when interactions were tested in the model. The gambler type and employment interaction was significant. Unlike the social support models, the interaction between gambler type and leisure complexity was not.

An analysis of the nature of the interaction showed that for those who are employed, there is no statistical difference in self-reported stress between LMR gamblers and recreational gamblers $(b=.10, S E=.17, p=.549$; see Fig. 5). However, for those who are not employed, life stress is significantly higher among LMR gamblers compared to recreational gamblers $(b=.51, S E=.16, p=.001$; see Fig. 5). Employment is associated with higher stress levels among older adults overall, but having a job tempers the extent to which older adult LMR gamblers experience heightened levels of life stress.

\section{Discussion}

Recreational and LMR gamblers have received relatively little attention when compared to problem gamblers, although the quality of life implications are important to

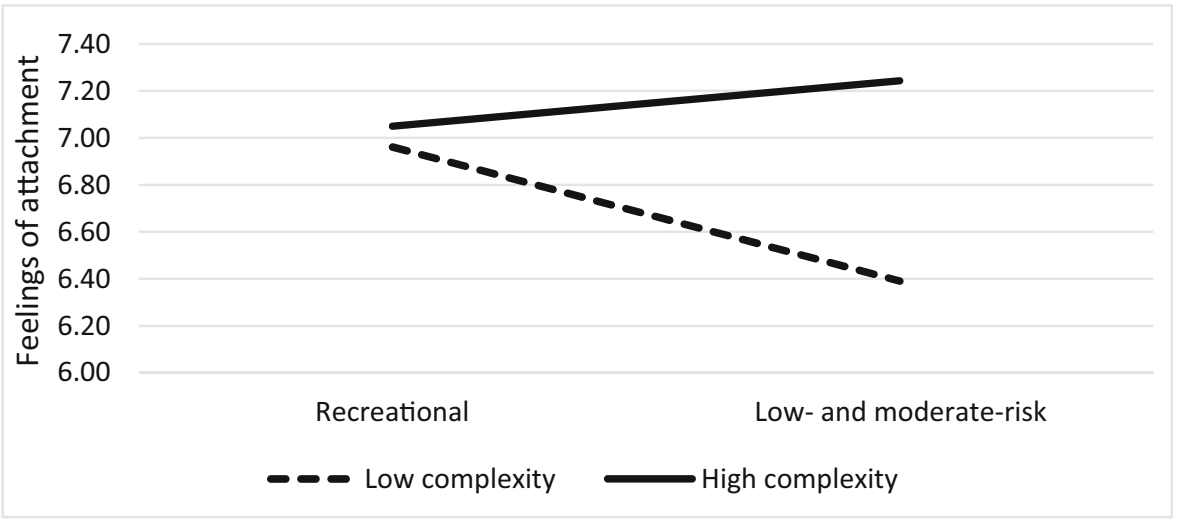

Fig. 4 Social attachment by type of gambler and leisure complexity (adults 55 years and older) 
Table 4 Unstandardized coefficients for regression models showing the association of selected demographics, activities, and interaction terms with life stress

\begin{tabular}{|c|c|c|c|c|c|c|}
\hline \multirow[t]{2}{*}{ Independent variables } & \multicolumn{2}{|l|}{ Model 1} & \multicolumn{2}{|l|}{ Model 2} & \multicolumn{2}{|l|}{ Model 3} \\
\hline & $\mathrm{B}$ & $\mathrm{SE}$ & $\mathrm{B}$ & SE & B & SE \\
\hline Constant & $5.65^{* * * *}$ & .25 & $4.361^{* * * *}$ & .27 & $4.34^{* * *}$ & .27 \\
\hline \multicolumn{7}{|l|}{ Demographics and health } \\
\hline Age & $-.04^{* * * *}$ & .00 & $-.02^{* * * *}$ & .00 & $-.02^{* * *}$ & .00 \\
\hline Gender $($ Male $=1)$ & $-.20^{* * * *}$ & .04 & $-.25^{* * *}$ & .04 & $-.25^{* * *}$ & .04 \\
\hline Partnered & -.08 & .04 & -.02 & .04 & -.02 & .04 \\
\hline Education & .05 & .04 & .06 & .04 & .06 & .04 \\
\hline Household income & $.09^{* * * *}$ & .02 & $.06^{* * * *}$ & .02 & $.06^{* *}$ & .02 \\
\hline Self-assessed health & $-.24^{* * * *}$ & .02 & $-.26^{* * * *}$ & .02 & $-.26^{* * * * *}$ & .02 \\
\hline \multicolumn{7}{|l|}{ Activities } \\
\hline Low or mod. risk gambler & & & $.30^{* * * *}$ & .08 & $.51^{* * * *}$ & .16 \\
\hline Leisure complexity & & & -.02 & .01 & -.02 & .01 \\
\hline Employed & & & $.48^{* * * * *}$ & .04 & $.50^{* * * *}$ & .04 \\
\hline \multicolumn{7}{|l|}{ Interactions } \\
\hline Gambler x employed & & & & & $-.41^{*}$ & .17 \\
\hline Gambler $\mathrm{x}$ leis. Complexity & & & & & -.01 & .05 \\
\hline Adj. $R^{2}$ & .098 & & .137 & & .138 & \\
\hline
\end{tabular}

$n=3162 ; * p<.05, * * p<.01, * * * p<.00$

consider. Older adults who are LMR gamblers may not experience individual outcomes as severe as problem gamblers, but because of their greater numbers they are responsible for more harm at the population level (Browne et al. 2016). Since the population of Canada is aging and the Baby Boom cohort remains sizable compared to other age groups (Bohnert et al. 2015), it is likely that the number of people who gamble will

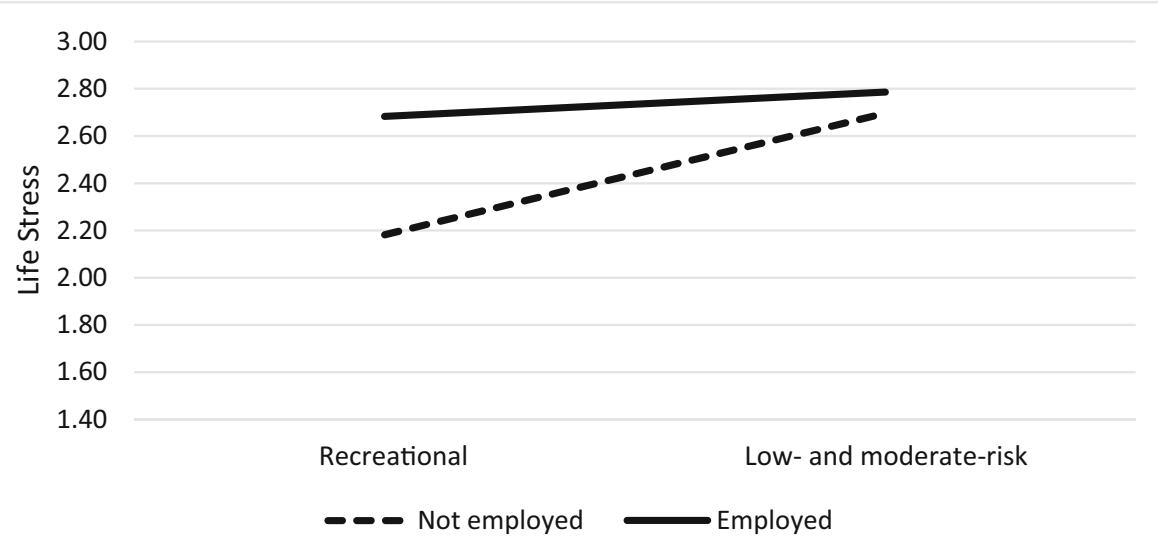

Fig. 5 Life stress by type of gambler and employment status (adults 55 years and older) 
increase, including those at low and moderate risk levels. In this context, it is also worth examining outcomes experienced by older adults who participate in recreational gambling to better understanding protective factors that contribute to quality of life (Tse et al. 2012). This group has been largely overlooked in previous research. Our findings show that older adult recreational gamblers experience higher levels of social support when compared to LMR gamblers. This is evident for both received support in the form of supportive guidance, and perceived support as represented by feelings of attachment. Lower levels of social support have been noted for problem gamblers (Cowlishaw et al. 2016), but are less well documented among LMR gamblers who may be motivated, in part, to gamble for social reasons or to cope with age-related transitions. In univariate analysis, the difference between groups for life stress was not significant, but when demographic factors and other activities were included in the analyses, life stress was significantly higher among LMR gamblers.

The demographic profile of older adult LMR gamblers in comparison to recreational gamblers had some similarities to problem gamblers: there were more men than women in this group, and a greater percentage was single rather than married or cohabiting (Southwell et al. 2008). In terms of age, education, household income level and selfassessed health, recreational and LMR gamblers were similar. When examining activities beyond gambling, there were significant differences in leisure complexity. Older adult recreational gamblers had more diverse leisure lifestyles, suggesting the ongoing importance of maintaining other social roles and physical activities, when possible, to enhance quality of life.

Social support is a protective factor for health and well-being throughout the life course (Cohen and Wills 1985). As people age, however, social networks diminish due to retirement, deaths of friends and loved ones, and leisure opportunities being limited or curtailed due to declining health, lack of transportation, or other factors (Strain et al. 2002). This may lead them to seek opportunities to connect with others, or to find alternate ways of coping. Social isolation and loneliness are particular problems among older adults, and gambling has been identified as a motivator for some people seeking social contact (Subramaniam et al. 2015). For retirees, recreational gambling can be a source of social support (Hope and Havir 2002). At the same time, longitudinal studies indicate detrimental impact of problem gambling relative to social support and family functioning (Cowlishaw et al. 2016). Our study indicates that recreational gamblers were more likely to report a close emotional bond with at least one other person. As such, they may be less likely to gamble as a way to address loneliness and social isolation. This type of social support could create conditions to keep gambling activities at the recreational level, without escalating into a risk category. For example, they may experience positive reinforcement from a significant other for keeping gambling behaviour in check, or negative feedback when relationship, financial, health, and other gambling-related harms become evident. Recreational gamblers were also more likely to have someone they felt they could ask for information and advice. A trusted confidant to whom the person could turn to for guidance could be an influential and protective factor if their gambling behaviour began to be of concern to themselves or others.

Participating in a variety of other leisure activities plays an important role for older adults who gamble. Recreational and LMR gamblers with high levels of leisure complexity enjoyed similarly high levels of social support, whereas LMR gamblers 
with lower leisure complexity reported significantly lower levels of social support when compared to their recreational counterparts. For some, activities such as a casino day trip or a game of mah-jong create conditions for developing or deepening social relationships. On the other hand, excessive time and/or money spent gambling limits participation in other leisure activities. As noted by Petry (2005), participating in activities other than gambling can lead to a broader social support network. This is consistent with activity theory, whereby quality of life among older adults is maintained or enhanced by pursuing or finding meaningful substitutes for activities enjoyed during middle age (Havighurst 1961). Further, participating in different activities is related to successful aging (Adams et al. 2010), especially when the activities are deemed important to individuals and their social networks (Nimrod 2007). It should be noted that the leisure activities included in the survey were limited to physically active leisure, and different relationships may exist for social, cultural, or other types of activities; however, physically active leisure among older adults is a known contributor to life satisfaction, positive affect, optimism, and overall well-being (Adams et al. 2010; Kim et al. 2017). Many "lifetime" physical activities included in the CCHS such as walking, swimming, or golfing are also highly social in nature (Mock and Hilbrecht 2013), thereby presenting opportunities to maintain or enhance social networks.

Employment also buffered the relationship between social support and gambler type, but to a lesser extent than leisure complexity. Beyond a providing a source of income, working is associated with other benefits such as social identity, regular activity, social contact, a sense of purpose and time structure, the absence of which can detract from quality of life (Jahoda 1982). Even though older adults may no longer wish to be employed, a lack of meaningful activity substitutes can lead to diminished social networks and well-being. Although LMR gamblers consistently reported lower levels of social support, it was significantly higher among those who were employed when compared to those no longer working. Many older adults remain employed because of opportunities for social contact, whether they are continuing in a main career or in bridge employment in a different work capacity (Gobeski and Beehr 2009). Beyond the financial benefits of regular employment to support continued gambling activities, the social contact inherent in most employment situations could be beneficial for LMR gamblers.

Our sample of older adults consisted of a "younger" group where the mean age was less than the traditional retirement age of 65 . Half of the sample was employed, although there was no way to know whether they were continuing with full-time employment or choosing bridge employment with fewer hours and a correspondingly lower rate of pay (Barnes-Farrell and Matthews 2007). Although working for pay buffered the relationship between gambler type and social support, the demands of employment can influence other aspects of well-being. Perhaps not surprisingly, we found that levels of life stress were higher for older adults with jobs regardless of gambler type. Recreational gamblers without jobs had the lowest levels of life stress, and there was little difference in higher stress levels found among employed LMR and employed recreational gamblers. Still, while employment may be somewhat protective for older adults in the LMR category, it is not necessarily the answer for people who are no longer interested in working or able to do so. For those who continue to work, employment represents an additional, differentiated role that can contribute to greater self-complexity and buffer the effects of stressful situations (Linville 1985, 1987). 
Leisure complexity appeared to be unrelated to life stress. It may be that while diverse leisure activities are associated positively with health among older adults (Stalker 2011), they may not always be correlated with lower stress levels. It could be that the effort, coordination, and other factors required to undertake multiple activities could contribute to stressful situations and effectively cancel out stressrelieving benefits associated with engaging in a variety of activities.

There are some limitations that should be considered when interpreting study findings. The data are cross-sectional and limit our ability to determine causality. Further, analyses included residents of Quebec only, a province with among the lowest gambling participation rates and rates of low, moderate, and problem gamblers in Canada (Canadian Partnership for Responsible Gambling 2015a, b). There may be cultural and regulatory factors in Quebec to be considered when compared to other jurisdictions. We would have preferred to include a wider range of leisure activities along with a measure of leisure experience since both would enhance leisure complexity and provide a more nuanced understanding of leisure among older adult gamblers. Further, more information about the social nature of gambling activities pursued by older adults would allow greater insight into perceptions of gambling as a social activity. Gambling at a formal venue such as a casino mostly among strangers, or as part of an informal social event (e.g., poker night with friends) would be qualitatively different experiences with implications for social support and well-being. More information about employment and perceptions of retirement "choice" among older adults who gamble could also lead to a better understanding of the buffering effect of working in later life. Finally, alternative measures of gambling risk could be employed. The PGSI has been critiqued as being less accurate than some other measures for older populations (Williams and Volberg 2014), and there is ongoing discussion about discriminate validity of the low and moderate risk categories (e.g., see Miller et al. 2013).

\section{Conclusion}

Gambling is a popular activity among older adults that has potential for growth as the population ages. Benefits have been identified for recreational gamblers, i.e., those who experience no problems related to gambling behaviours and attitudes, but there are a number of social, financial, and health harms affecting quality of life that are related to gambling across the spectrum of risk levels. Since both recreational and LMR groups have been largely overlooked in past, we were interested in exploring the ways in which they differed in order to gain insights about protective factors associated with recreational gamblers since it is now recognized that the larger numbers of low and moderate risk older adult gamblers are responsible for greater amounts of harm at the population level (Browne et al. 2016). Furthermore, we know little about these groups when compared to the more extensive literature on older adult problem gamblers.

Our study was an initial foray into understanding the role of activities that might contribute to self-complexity, such as employment and active leisure participation, that buffer the relationship between gambling behaviour and well-being. We found that recreational gamblers enjoy higher levels of supportive guidance in terms of informal information and advice, and have stronger feelings of attachment or, emotional 
closeness, to other people in their lives. Participating in a greater variety of leisure activities and remaining employed created conditions for stronger received and perceived social support. Life stress was higher among older adults who worked for pay. Even so, having a job appeared to temper stress levels among LMR gamblers, although it is understandable that many older adults may prefer not to remain employed at this stage of their lives.

We encourage further research examining the role of leisure among older adults who gamble. While the vast majority report positive experiences, it is important not to overlook those with low to moderate risk behaviour. Greater attention could be given to ensuring that there are easily accessible, alternate leisure choices, especially for older adults with reduced social roles and other activities in their lives. Further, ensuring employment remains an option for those who wish to continue working could be encouraged in government and workplace policies.

Compliance with Ethical Standards This study is a secondary analysis of Statistics Canada data. For this type of study formal consent is not required.

Conflict of Interest The authors declare they have no potential conflicts of interest.

Open Access This article is distributed under the terms of the Creative Commons Attribution 4.0 International License (http://creativecommons.org/licenses/by/4.0/), which permits unrestricted use, distribution, and reproduction in any medium, provided you give appropriate credit to the original author(s) and the source, provide a link to the Creative Commons license, and indicate if changes were made.

\section{References}

Abbott, M., Binde, P., Clark, L., Hodgins, D., Pereira, A., Quilty, L., ... Williams, R. J. (2015). Conceptual framework of harmful gambling: An international collaboration (Rev. Ed.). Guelph: Gambling Research Exchange Ontario.

Adams, K. B., Leibbrandt, S., \& Moon, H. (2010). A critical review of the literature on social and leisure activity and well-being in later life. Ageing and Society, 31(4), 683-712. https://doi.org/10.1017 /S0144686X10001091.

American Psychiatric Association. (2013). Diagnostic and statistical manual of mental disorders: DSM-5 (5th ed.). Washington, DC: American Psychiatric Publishing.

Ariyabuddhiphongs, V. (2012). Older adults and gambling: a review. International Journal of Mental Health and Addiction, 10(2), 297-308. https://doi.org/10.1007/s11469-011-9325-6.

Ashe, M. C., Miller, W. C., Eng, J. J., \& Noreau, L. (2008). Older adults, chronic disease and leisure-time physical activity. Gerontology, 55(1), 64-72.

Barnes-Farrell, J. L., \& Matthews, R. (2007). Age and work attitudes. In K. S. Shultz \& G. A. Adams (Eds.), Aging and work in the 21st century (pp. 139-162). Mahwah, NJ: Lawrence Erlbaum Associates.

Barrera, M. (1986). Distinctions between social support concepts, measures, and models. American Journal of Community Psychology, 14(4), 413-445. https://doi.org/10.1007/BF00922627.

Bohnert, N., Chagnon, J., \& Dion, P. (2015). Population projections for Canada (2013 to 2063), Provinces and territories (2013 to 2038) (Statistics Canada Cat. No. 91-520-X). Retrieved from http://www.statcan. gc.ca/pub/91-520-x/91-520-x2014001-eng.pdf.

Browne, M., Langham, E., Rawat, V., Greer, N., Li, E., Rose, J., ... Best, T. (2016). Assessing gamblingrelated harm in Victoria: A public health perspective. Retrieved from Melbourne, AU: https://www. responsiblegambling.vic.gov.au/_data/assets/pdf_file/0007/28465/Browne_assessing_gambling-related_ harm_in_Vic_Apr_2016-REPLACEMENT2.pdf. 
Canadian Partnership for Responsible Gambling (2015a). The Digest - Gambling participation. 2015-2016 Digest. Retrieved from http:/www.cprg.ca/Digests/ViewCards?mainCellId=b888b81e-e5bf-e611-b52a$1 \mathrm{abbb38a3094.}$

Canadian Partnership for Responsible Gambling (2015b). The Digest - Problem gambling prevalence. 20152016 Digest. Retrieved from http:/www.cprg.ca/Digests/ViewCards?mainCellId=0b7fb81e-e5bf-e611b52a-1abbb38a3094.

Caron, J. (1996). L'Échelle de provisions sociales : Une validation québécoise. Santé Mentale au Québec, 21(2), 158-180.

Cohen, S., \& Wills, T. A. (1985). Stress, social support, and the buffering hypothesis. Psychological Bulletin, 98, 310-357. https://doi.org/10.1037/0033-2909.98.2.310.

Cowlishaw, S., Suomi, A., \& Rodgers, B. (2016). Implications of gambling problems for family and interpersonal adjustment: results from the Quinte longitudinal study. Addiction, 111(9), 1628-1636. https://doi.org/10.1111/add.13402.

Cummins, R. A. (2000). Objective and subjective quality of life: an interactive model. Social Indicators Research, 52(1), 55-72. https://doi.org/10.1023/A:1007027822521.

Currie, S. R., Miller, N., Hodgins, D. C., \& Wang, J. (2009). Defining a threshold of harm from gambling for population health surveillance research. International Gambling Studies, 9(1), 19-38. https://doi. org/10.1080/14459790802652209.

Currie, S. R., Hodgins, D. C., \& Casey, D. M. (2013). Validity of the problem gambling severity index interpretive categories. Journal of Gambling Studies, 29(2), 311-327. https://doi.org/10.1007/s10899012-9300-6.

Cutrona, C. E., \& Russell, D. W. (1987). The provisions of social relationships and adaptation to stress. Advances in Personal Relationships, 1(1), 37-67.

Delfabbro, P., \& King, D. (2017). Prevention paradox logic and problem gambling: does low-risk gambling impose a greater burden of harm than high-risk gambling? Journal of Behavioral Addictions, 6(2), 163167. https://doi.org/10.1556/2006.6.2017.022.

Desai, R. A., Maciejewski, P. K., Dausey, D. J., Caldarone, B. J., \& Potenza, M. N. (2004). Health correlates of recreational gambling in older adults. American Journal of Psychiatry, 161(9), 1672-1679. https://doi. org/10.1176/appi.ajp.161.9.1672.

Desai, R. A., Desai, M. M., \& Potenza, M. N. (2007). Gambling, health and age: data from the National Epidemiologic Survey on alcohol and related conditions. Psychology of Addictive Behaviors, 21(4), 431440. https://doi.org/10.1037/0893-164X.21.4.431.

DeSalvo, K. B., Fisher, W. P., Tran, K., Bloser, N., Merrill, W., \& Peabody, J. (2006). Assessing measurement properties of two single-item general health measures. Quality of Life Research, 15(2), 191-201. https://doi.org/10.1007/s11136-005-0887-2.

Erickson, L., Molina, C. A., Ladd, G. T., Pietrzak, R. H., \& Petry, N. M. (2005). Problem and pathological gambling are associated with poorer mental and physical health in older adults. International Journal of Geriatric Psychiatry, 20(8), 754-759. https://doi.org/10.1002/gps.1357.

Farrell, L. (2017). Understanding the relationship between subjective well-being and gambling behavior. Journal of Gambling Studies., 34, 55-71. https:/doi.org/10.1007/s10899-017-9692-4.

Ferris, J., \& Wynne, H. (2001). The Canadian Problem Gambling Index. Ottawa, ON: Canadian Centre on Substance Abuse.

Gobeski, K. T., \& Beehr, T. A. (2009). How retirees work: predictors of different types of bridge employment. Journal of Organizational Behavior, 30(3), 401-425. https://doi.org/10.1002/job.547.

Hancock, L., \& Smith, G. (2017). Critiquing the Reno model I-IV: international influence on regulators and governments (2004-2015) - the distorted reality of "responsible gambling". International Journal of Mental Health and Addiction, 15, 1-26. https://doi.org/10.1007/s11469-017-9746-y.

Havighurst, R. J. (1961). Successful aging. The Gerontologist, 1(1), 8-13. https://doi.org/10.1093 /geront/1.1.8.

Hayes, A. F. (2013). Introduction to mediation, moderation, and conditional process analysis. New York: Guilford Press.

Hope, J., \& Havir, L. (2002). You bet they're having fun! Older Americans and casino gambling. Journal of Aging Studies, 16(2), 177-197. https://doi.org/10.1016/S0890-4065(02)00043-9.

Iwasaki, Y. (2003). The impact of leisure coping beliefs and strategies on adaptive outcomes. Leisure Studies, 22(2), 93-108.

Jahoda, M. (1982). Employment and unemployment: A social psychological analysis. Cambridge, UK: Cambridge University Press.

Kairouz, S., Nadeau, L., \& Robillard, C. (2014). Portrait du jeu au Québec: Prévalence, incidence et trajectoires sur quatre ans. Retrieved from Montreal, QC: https://www.concordia. 
$\mathrm{ca} /$ content/dam/artsci/research/lifestyle-addiction/docs/projects/enhjeu-q/ENHJEU-QC-2012_rapportfinal-FRQ-SC.pdf.

Kaplan, G. A., \& Camacho, T. (1983). Perceived health and mortality: a nine-year follow up of the human population laboratory cohort. American Journal of Epidemiology, 117(3), 292-304. https://doi. org/10.1093/oxfordjournals.aje.a113541.

Kekäläinen, T., Wilska, T.-A., \& Kokko, K. (2017). Leisure consumption and well-being among older adults: does age or life situation matter? Applied Research in Quality of Life, 12(3), 671-691. https://doi. org/10.1007/s11482-016-9483-6.

Kim, J., Lee, S., Chun, S., Han, A., \& Heo, J. (2017). The effects of leisure-time physical activity for optimism, life satisfaction, psychological well-being, and positive affect among older adults with loneliness. Annals of Leisure Research, 20(4), 406-415. https://doi.org/10.1080/11745398.2016.1238308.

Korn, D. A. (2000). Expansion of gambling in Canada: implications for health and social policy. Canadian Medical Association. Journal, 163(1), 61-64.

Krueger, A. B., \& Schkade, D. A. (2008). The reliability of subjective well-being measures. Journal of Public Economics, 92(8), 1833-1845. https://doi.org/10.1016/j.jpubeco.2007.12.015.

Ladd, G. T., Molina, C. A., Kerins, G. J., \& Petry, N. M. (2003). Gambling participation and problems among older adults. Journal of Geriatric Psychiatry and Neurology, 16(3), 172-177. https://doi.org/10.1177 $/ 0891988703255692$.

Langham, E., Thorne, H., Browne, M., Donaldson, P., Rose, J., \& Rockloff, M. (2016). Understanding gambling related harm: a proposed definition, conceptual framework, and taxonomy of harms. $B M C$ Public Health, 16(1), 80. https://doi.org/10.1186/s12889-016-2747-0.

Lemon, B. W., Bengtson, V. L., \& Peterson, J. A. (1972). An exploration of the activity theory of aging: activity types and life satisfaction among in-movers to a retirement community. Journal of Gerontology: Psychological Sciences, 27(4), 511-523. https://doi.org/10.1093/geronj/27.4.511.

Linville, P. W. (1985). Self-complexity and affective extremity: don't put all of your eggs in one cognitive basket. Social Cognition, 3(1), 94-120. https://doi.org/10.1521/soco.1985.3.1.94.

Linville, P. W. (1987). Self-complexity as a cognitive buffer against stress-related illness and depression. Journal of Personality and Social Psychology, 52(4), 663-676. https://doi.org/10.1037/00223514.52.4.663.

Mannell, R. C., \& Manske, S. R. (2010). Leisure and the development of complexity. In L. Payne, B. Ainsworth, \& G. Godbey (Eds.), Leisure, health, and wellness: making the connections (pp. 179-187). State College: Venture Publishing, Inc.

McCready, J., Mann, R. E., Zhao, J., \& Eves, R. (2008). Correlates of gambling-related problems among older adults in Ontario. Journal of Gambling Studies, 22, 174-194. https://doi.org/10.4309/jgi.2008.22.3.

McKay, C. (2005). Double jeopardy: older women and problem gambling. International Journal of Mental Health and Addiction, 3(2), 35-53.

McMillen, J. (1996). Understanding gamblng: History, conepts and theories. In J. McMillen (Ed.), Gambling cultures: Studies in history and interpretation (pp. 6-39). New York: Routledge.

McNeilly, D. P., \& Burke, W. J. (2001). Gambling as a social activity of older adults. The International Journal of Aging and Human Development, 52(1), 19-28. https://oi.org/10.2190/A4U7-234X-B3XP-64 AH.

Miller, N. V., Currie, S. R., Hodgins, D. C., \& Casey, D. (2013). Validation of the problem gambling severity index using confirmatory factor analysis and rasch modelling. International Journal of Methods in Psychiatric Research, 22(3), 245-255. https://doi.org/10.1002/mpr.1392.

Mock, S. E., \& Hilbrecht, M. (2013). Association of dual-earner parents' perceptions of time-stress with leisure participation: an analysis of gender and social context. World Leisure Journal, 55(1), 24-37. https://doi.org/10.1080/04419057.2012.720586.

Nimrod, G. (2007). Retirees' leisure: activities, benefits, and their contribution to life satisfaction. Leisure Studies, 26(1), 65-80. https://doi.org/10.1080/02614360500333937.

Petry, N. M. (2005). Pathological gambling: Etiology, comorbidity, and treatment. Washington, DC: American Psychological Association.

Pietrzak, R. H., \& Petry, N. M. (2006). Severity of gambling problems and psychosocial functioning in older adults. Journal of Geriatric Psychiatry and Neurology, 19(2), 106-113. https://doi.org/10.1177 /0891988706286508.

Pietrzak, R. H., Morasco, B. J., Blanco, C., Grant, B. F., \& Petry, N. M. (2007). Gambling level and psychiatric and medical disorders in older adults: results from the National Epidemiologic Survey on alcohol and related conditions. The American Journal of Geriatric Psychiatry, 15(4), 301-313. https://doi. org/10.1097/01.JGP.0000239353.40880.cc. 
Robins, R. W., Hendin, H. M., \& Trzesniewski, K. H. (2001). Measuring global self-esteem: construct validation of a single-item measure and the Rosenberg self-esteem scale. Personality and Social Psychology Bulletin, 27(2), 151-161. https://doi.org/10.1177/0146167201272002.

Shaffer, H. J. (2003). A public health perspective on gambling: The four principles. AGA Responsible Gaming Lecture Series, 2003(2), 1-27.

Shaffer, H. J., \& Korn, D. A. (2002). Gambling and related mental disorders: a public health analysis. Annual Review of Public Health, 23(1), 171-212. https://doi.org/10.1146/annurev.publhealth.23.100901.140532.

Shen, Y., Kairouz, S., Nadeau, L., \& Robillard, C. (2014). Comparing problem gamblers with moderate-risk gamblers in a sample of university students. Journal of Behavioral Addictions, 4(2), 53-59. https://doi. org/10.1556/2006.4.2015.002.

Southwell, J., Boreham, P., \& Laffan, W. (2008). Problem gambling and the circumstances facing older people. Journal of Gambling Studies, 24(2), 151-174. https://doi.org/10.1007/s10899-007-9079-z.

Stalker, G. J. (2011). Leisure diversity as an indicator of cultural capital. Leisure Sciences, 33(2), 81-102. https://doi.org/10.1080/01490400.2011.550219.

Statistics Canada. (2015). Canadian Community Health Survey (CCHS) annual component: User guide 2014 and 2013/2014 microdata files. Ottawa: Government of Canada.

Strain, L. A., Grabusic, C. C., Searle, M. S., \& Dunn, N. J. (2002). Continuing and ceasing leisure activities in later life: a longitudinal study. The Gerontologist, 42, 217-223. https://doi.org/10.1093/geront/42.2.217.

Subramaniam, M., Wang, P., Soh, P., Vaingankar, J. A., Chong, S. A., Browning, C. J., \& Thomas, S. A. (2015). Prevalence and determinants of gambling disorder among older adults: a systematic review. Addictive Behaviors, 41, 199-209. https://doi.org/10.1016/j.addbeh.2014.10.007.

Tse, S., Hong, S.-I., Wang, C.-W., \& Cunningham-Williams, R. M. (2012). Gambling behavior and problems among older adults: a systematic review of empirical studies. The Journals of Gerontology. Series B, 67(5), 639-652. https://doi.org/10.1093/geronb/gbs068.

van der Maas, M., Mann, R. E., McCready, J., Matheson, F. I., Turner, N. E., Hamilton, H. A., Schrans, T., \& Ialomiteanu, A. (2016). Problem gambling in a sample of older adult casino gamblers: associations with gambling participation and motivations. Journal of Geriatric Psychiatry and Neurology, 30(1), 3-10. https://doi.org/10.1177/0891988716673468.

van der Maas, M., Mann, R. E., Matheson, F. I., Turner, N. E., Hamilton, H. A., \& McCready, J. (2017). A free ride? An analysis of the association of casino bus tours and problem gambling among older adults. Addiction, 112, 2217-2224. https://doi.org/10.1111/add.13914.

Vander Bilt, J., Dodge, H. H., Pandav, R., Shaffer, H. J., \& Ganguli, M. (2004). Gambling participation and social support among older adults: a longitudinal community study. Journal of Gambling Studies, 20(4), 373-389. https://doi.org/10.1007/s10899-004-4580-0.

Williams, R. J., \& Volberg, R. A. (2013). Gambling and problem gambling in Ontario. Retrieved from https://www.uleth.ca/dspace/bitstream/handle/10133/3378/2013-GPG\%20ONT-OPGRC. pdf? sequence $=3$.

Williams, R. J., \& Volberg, R. A. (2014). The classification accuracy of four problem gambling assessment instruments in population research. International Gambling Studies, 14(1), 15-28. https://doi.org/10.1080 /14459795.2013.839731.

Williams, R. J., Hann, R., Schopflocher, D., West, B., McLaughlin, P., White, N., ... Flexhaug, T. (2015). Quinte longitudinal study of gambling and problem gambling: Report prepared for the Ontario Problem Gambling Research Centre. Retrieved from http://www.greo. ca/Modules/EvidenceCentre/files/Williams\%20et\%20al\%20\%282015\%29Quinte_longitudinal_ study_of_gambling_and_PG.pdf.

Zaranek, R. R., \& Chapleski, E. E. (2005). Casino gambling among urban elders: Just another social activity? Journals of Gerontology. Series B, Psychological Sciences and Social Sciences, 60B(2), S74-S81. 